\title{
CRY-BARs: Versatile light-gated molecular tools for the remodeling of membrane architectures
}

Anna I. Wurz ${ }^{\dagger}$, Wyatt Paul Bunner $\neq$, Erzsebet M. Szatmari ${ }^{\ddagger}$, Robert M. Hughes ${ }^{\dagger *}$

${ }^{\dagger}$ Department of Chemistry, East Carolina University, Greenville, North Carolina, United States

‡ Department of Physical Therapy, East Carolina University, Greenville, North Carolina, United States

*Contact: hughesr16@ecu.edu

\section{RUNNING TITLE: Light activated membrane remodeling}

\section{Abstract}

BAR (Bin, Amphiphysin and Rvs) protein domains are responsible for the generation of membrane curvature and represent a critical mechanical component of cellular functions. Thus, BAR domains have great potential as components of membrane-remodeling tools for cell biologists. In this work, we describe the design and implementation of a family of versatile lightgated I-BAR domain containing tools ('CRY-BARs') with applications in the remodeling of membrane architectures and the control of cellular dynamics. By taking advantage of the intrinsic membrane binding propensity of the I-BAR domain, CRY-BARs can be used for spatial and temporal control of cellular processes that require induction of membrane protrusions. Using cell lines and primary neuron cultures, we demonstrate that the CRY-BAR optogenetic tool reports membrane dynamic changes associated with cellular activity. Moreover, we provide evidence that Ezrin acts as a relay between the plasma membrane and the actin cytoskeleton and therefore is an important mediator of switch function. Overall, CRY-BARs hold promise as a useful addition to the optogenetic toolkit to study membrane remodeling in live cells.

\section{INTRODUCTION}

Membrane bound architectures, including filopodia, lamellipodia, and dendritic spines in neurons, are critical for a cell's ability to transmit and respond to extracellular cues. As such, chemists and biologists have developed numerous optogenetic and chemo-optogenetic tools to control cellular architectures via manipulation of plasma membrane dynamics (Kichuk, Carrasco-López, \& Avalos, 2021; Klewer \& Wu, 2019; Ueda \& Sato, 2018). However, these tools have to date incorporated a relatively small fraction of the numerous proteins involved in the building and dismantling of these architectural features. In particular, non-enzymatic proteins have been overlooked: while numerous optogenetic strategies exist for enzyme-mediated control of membrane dynamics (Khamo, Krishnamurthy, Chen, Diao, \& Zhang, 2019; C.P. O'Banion et al., 2017; Colin P O’Banion, Vickerman, Haar, \& Lawrence, 2019; Shaaya et al., 2020; Wu et al., 2009; Wu, Wang, He, Montell, \& Hahn, 2011), far fewer have incorporated non-enzymatic proteins as the basis of optogenetic switch action (Redchuk et al., 2020). As 
mechanical control of membrane architecture by non-enzymatic proteins is a critical component of cellular signaling (Hughes \& Kumar, 2016), addressing this oversight will be a bridge to a more comprehensive understanding of cellular dynamics and function.

In recent years, the critical role of proteins involved in membrane curvature inducing and sensing has come to light (Antonny, 2011). In particular, BAR domain containing proteins possess diverse activities at the plasma membrane (Linkner et al., 2014; Prévost et al., 2015; Pykäläinen et al., 2011; Saarikangas et al., 2015, 2011; Yu et al., 2011; Zhao, Pykäläinen, \& Lappalainen, 2011); as such, a heightened understanding of these roles has invited recent investigations of their suitability for control with optogenetic tools (Jones, Liu, \& Cui, 2020). In this work, we investigate the potential of an inverse BAR (I-BAR) domain from the MTSS1 protein (Missing in Metastasis 1) to serve as an actuator of membrane architecture and plasma membrane dynamics. We demonstrate that the I-BAR domain from MTSS1, in conjunction with the Cry2 optogenetic switch (Kennedy et al., 2010), is the basis of a versatile optogenetic approach ('CRY-BAR') for controlling membrane dynamics and cellular architecture. We also provide insight into the mode of action of CRY-BAR by showing that Ezrin, a membrane and cytoskeletal relay protein, is linked to CRY-BAR's ability to induce light-activated membrane remodeling and spatial restriction of cellular dynamics.

\section{MATERIALS AND METHODS}

\section{Plasmids and Cloning}

Cloning of IBAR.Cry2PHR.mCh, Cry2PHR.mCh.IBAR, IBAR.Cry2PHR.mCh.WH2, and Cry2PHR.mCh.MTSS1 constructs was conducted using a previously described cloning scheme (Salem et al., 2020). Briefly, the IBAR domain from MTSS1, the WH2 domain from MTSS1, and MTSS1 were PCR amplified from human MTSS1 cDNA obtained from the Arizona State University DNA repository (DNASU ID HsCD00746054). N-terminal IBAR genes were cloned into Cry2PHR.mCherry (Addgene \#26866) using Nhel and Xhol restriction sites (Kennedy et al., 2010). C-terminal IBAR, WH2, and MTSS1 genes were cloned into Cry2PHR.mCherry using BsrgI and Notl restriction sites. Ezrin-GFP was expressed from plasmid pHJ421 (Addgene \#20680) (Hao et al., 2009). Midi prep quantities of DNA of each construct were created from E. coli and collected for cell transfection.

\section{Cell lines and Transfection}

HEK293T cells (passage 8) used for these experiments were purchased from ATCC and were cultured in DMEM medium containing 10\% FBS and 1\% Penicillin-Streptomycin. Cultures were transfected at $70 \%$ confluency with the Lipofectamine 3000 reagent (Invitrogen) following manufacturer's suggested protocols. Briefly, for dual transfections in $35 \mathrm{~mm}$ glass bottom dishes for cell imaging or 6-well culture plates for lysis, plasmid DNA was combined in a 1:1 ratio (1,250 ng per plasmid) in $125 \mu$ l of Opti-Mem, followed by the addition of $5 \mu \mathrm{l}$ of P3000 reagent. For single transfections, 2,500 ng of plasmid DNA was used per transfection. In a separate vial, $3.75 \mu \mathrm{l}$ of Lipofectamine 3000 were added to $125 \mu \mathrm{l}$ of Opti-Mem. The two $125 \mu \mathrm{l}$ solutions were combined and allowed to incubate at room temperature for $10 \mathrm{~min}$, followed by dropwise addition to cell culture. Transfection solutions remained on cells overnight. 
Transfected cells were maintained at $37^{\circ} \mathrm{C}$ and $5 \% \mathrm{CO}_{2}$ in a humidified tissue culture incubator, in culture medium consisting of DMEM supplemented with $10 \%$ FBS and $1 \%$ PenicillinStreptomycin.

\section{Neuron cultures and Transfection}

Postnatal dissociated cortical neuron cultures were prepared as previously described (Bunner, Dodson, Szatmari, \& Hughes, 2021; Chang et al., 2017), from newborn B6 mice. Neurons were plated into $35 \mathrm{~mm}$ glass bottom Petri dishes at a $1 \mathrm{million} / \mathrm{ml}$ density in culture medium consisting of BME supplemented with $10 \%$ BCS and $1 \%$ Penicillin-Streptomycin. On day in vitro 2 (DIV2), culture medium was changed to Neurobasal A medium, supplemented with B27-plus reagent (Invitrogen), Glutamax and 1\% Penicillin-Streptomycin. Neurons were transfected with the CryBAR optogenetic system ( $6 \mu \mathrm{g}$ plasmid/plate) on DIV5 using Lipofectamine LTX reagent (Invitrogen). On DIV7, culture medium was removed and neurons were placed in imaging solution (Mg-free HEPES buffered aCSF (Sun, Smirnov, Kamasawa, \& Yasuda, 2021)) Live cell imaging was performed before and after illumination using a Leica DMi8 Live Cell Imaging System.

\section{Fixed and Live-cell Imaging Preparation}

Fixed cell experiments: Immediately prior to fixation, transfected HEK293T cells were either kept in dark conditions or illuminated with LED blue light for $5 \mathrm{~min}$. Cells were washed with Dulbecco's PBS (with calcium and magnesium; $1 \times 1 \mathrm{~mL}$ ), then fixed for $10 \mathrm{~min}$ at room temperature with pre-warmed $4 \%$ Paraformaldehyde solution in DPBS $\left(37^{\circ} \mathrm{C}\right.$; prepared from 16\% PFA (Electron Microscopy Sciences)). Following fixation, cells were washed with DPBS, then stored in DPBS at $4^{\circ} \mathrm{C}$.

Live cell experiments: Transfected HEK293T cell media was replaced with 10\% FBS in Leibovitz's L-15 Medium. Cells were allowed to equilibrate in the live cell incubation system (OKOLab) for 10 minutes prior to beginning the illumination sequence.

\section{Imaging}

Confocal Microscopy: Confocal images of fixed cells were collected with a Zeiss LSM 700 laser scanning microscope using ZEN Black 2012 software. Fluorescence images were colorized and overlaid using FIJI software.

Widefield Microscopy: A Leica DMi8 Live Cell Imaging System, equipped with an OKOLab stagetop live cell incubation system, LASX software, Leica HCX PL APO 63x/1.40-0.60na oil objective, Lumencor LED light engine, CTRadvanced+ power supply, and a Leica DFC900 GT camera, was used to acquire images. Exposure times were set at $200 \mathrm{~ms}$ (mCherry, $550 \mathrm{~nm}$ ) and $50 \mathrm{~ms}$ (GFP, $480 \mathrm{~nm}$ ), with LED light sources at 50\% power, and images acquired every 30 seconds over specified time course.

\section{Western blotting}


Transfected HEK293T cells were lysed with $200 \mu \mathrm{L}$ of M-PER lysis buffer (Thermo Scientific) containing 1X Halt protease-phosphatase inhibitor cocktail (Thermo Scientific). After 10 min on a rotary shaker at room temperature, lysates were collected and centrifuged for 15 min (94 rcf; $4^{\circ} \mathrm{C}$ ). The supernatants were combined with Laemmli SDS sample buffer (Alfa Aesar) and incubated at $65^{\circ} \mathrm{C}$ for $10 \mathrm{~min}$. The resulting lysates were subjected to electrophoresis on a $10 \%$ SDS-PAGE gel and then transferred onto PVDF membranes (20 V, $800 \mathrm{~min}$ ). Membranes were then blocked for $1 \mathrm{~h}$ with 5\% BSA in 1x TBS with 1\% Tween (TBST), followed by incubation with primary antibody (Anti-mCherry antibody (Cell Signaling) 1:1000 dilution in 5\% BSA - TBST; Anti-GAPDH antibody (Invitrogen) 1:1000 dilution in 5\% BSA - TBST) overnight at $4{ }^{\circ} \mathrm{C}$ on a platform rocker. The membranes were then washed $3 x$ for 5 min each with TBST and incubated with the appropriate secondary antibody in 5\% BSA - TBST ( $1 \mathrm{~h}$; room temperature). After washing $3 x$ for 5 min with TBST, the membranes were exposed to a chemiluminescent substrate for 5 min and imaged with an Azure cSeries imaging station.

\section{Results and Discussion}

Increased MTSS-1 activity has been associated with exercise-induced enhancement of synaptic function (Chatzi et al., 2019). This pro-synaptic plasticity effect of MTSS-1 is attributed to the presence of an I-BAR domain within its structure. Moreover, I-BAR domains have also been shown to promote formation and stabilization of dendritic spines (Fig. 1A), leading to improved synaptic function and resilience against neurodegeneration (Saarikangas et al., 2015). To gain insights into the molecular mechanisms that control membrane expansion associated with cell morphology changes, we incorporated the I-BAR domain from MTSS-1 into a light-activated optogenetic protein (Cry2PHR; Fig. 1B-C), creating a light-activatable I-BAR protein (CRY-BAR). For this investigation, we engineered four permutations of the CRY-BAR switch: IBAR-Cry2-mCh, IBAR-Cry2-mCh-WH2, Cry2-mCh-IBAR, and Cry2-mCh-MTSS1 (Fig. 1C). Each construct was confirmed by Sanger and NextGen sequencing and expressed at the expected molecular weight (Supporting Fig. 1).

CRY-BAR constructs were initially probed for their response to blue light in the presence of CIBCAAX, a membrane localized binding partner to Cry2, in HEK293T cells. As anticipated, light activation of the Cry2-PHR control resulted in rapid recruitment to the plasma membrane (Fig. $\mathbf{2 A}$ and $\mathbf{3 A}$ ). By contrast, the I-BAR domain containing constructs exhibited less apparent lightactivated recruitment to the plasma membrane (Fig. 2A , 2C, and $\mathbf{3 B}$ ). We attributed this to the PIP2-binding propensity of the I-BAR domain, which results in significant pre-localization of the CRY-BAR constructs (readily observed in the pre-illumination images in Fig. $2 \mathrm{~A}$ and $\mathbf{2 C}$ ). Due to the significant pre-localization of these constructs, we then investigated whether they might exhibit light activation in the absence of CIB-CAAX. These experiments revealed significant light activated clustering/membrane recruitment (Fig. 2B and 2D) in the absence of CIB-CAAX. This effect was observed for all of the I-BAR containing constructs with the exception of Cry2-mChMTSS1, which accumulated primarily in non-light responsive clusters. As a result, this construct was not pursued further. 
Homo-oligomerization of the CRY-BAR constructs IBAR-Cry2-mCh and Cry2-mCh-IBAR results in membrane deformation and restriction of cellular dynamics (Supporting Movies 1A and 1B). These effects are reversible in the dark. To demonstrate this using Cry2-mCh-IBAR, we conducted a $10 \mathrm{~min}$ light activation sequence, followed by a $30 \mathrm{~min}$ observation period in the absence of blue light. Rapid restriction of membrane dynamics was observed during the 10 min blue light activation period, with full reversibility of membrane rounding achieved after $30 \mathrm{~min}$ in the absence of blue light (Fig. 4; Supporting Movie 2). We subsequently demonstrated that this effect can be selectively induced using localized illumination of the cell on a confocal microscope (Fig. 5, Supporting Movie 3). We also investigated whether the presence of a WH2 domain (present in IBAR-Cry2Phr-mCh-WH2, but not in IBAR-Cry2Phr-mCh and Cry2Phr-mChIBAR) impacted the membrane remodeling capabilities of the optogenetic switch. Light activation of a N-terminal I-BAR domain without a C-terminal WH2 domain (IBAR-Cry2Phr-mCh) promoted its accumulation in numerous filopodia-like protrusions that rapidly coalesced with continued light exposure (Fig. 6A). By contrast, light activation of a N-terminal I-BAR domain with a C-terminal $\mathrm{WH} 2$ domain, while not diminishing the overall light responsivity of the protein fusion (Fig. 2A and 2B) inhibited pronounced filopodial accumulation (Fig. 6B). This result may illustrate competing functions of critical MTSS-1 protein domains, where the I-BAR domain is required for membrane binding, and the $\mathrm{WH} 2$ domain is required for recruitment of actin polymerizing components that promote protrusion formation and elongation (Saarikangas et al., 2011). Finally, a side-by-side comparison of light activation of IBAR-Cry2Phr-mCh, IBARCry2Phr-mCh-WH2, and Cry2Phr-mCh-IBAR demonstrated that more robust membrane remodeling activity is associated with light activation of Cry2Phr-mCh-IBAR (Supporting Movie 4). This is likely due to enhanced PIP2 binding ability of the IBAR domain when in the C-terminal position of the optogenetic fusion protein.

We postulated that the dynamic membrane-remodeling activity observed with CRY-BARs might be due to its interaction with proteins that link the plasma membrane with the cytoskeleton. Ezrin is one such protein that has both lipid binding and cytoskeleton binding domains (Tsai et al., 2018). We hypothesized that clustering of the PIP2-bound CRY-BARs might impact dynamics by also clustering Ezrin, resulting in restriction of cytoskeletal-associated phenomenon such as membrane ruffling. To investigate this, we co-transfected Cry2Phr-mCh-IBAR with an Ezrin-GFP fusion. In the presence of light, we observed co-localization of Ezrin-GFP with Cry2Phr-mChIBAR clusters at the plasma membrane (Fig. 7). This effect was pronounced in the light, and absent in the dark, indicating that CRY-BAR activation actively restricts Ezrin dynamics. Cry-BAR activation accompanied by Ezrin sequestration also resulted in increased cell thickness (Fig. 8), with no such effect being observed in cells expressing the Cry2Phr control.

Having investigated the CRY-BAR response in immortalized cell culture, we next evaluated the capability of the sensor to report membrane expansion dynamics in neurons. For this, dissociated postnatal cortical neuron cultures prepared from newborn mice were cotransfected with CIB-GFP-CAAX according to protocol we developed for expressing optogenetic sensors in primary cultures (Bunner et al., 2021). Light activation of Cry2Phr-mCh-IBAR, but not 
Cry2PHR resulted in elongation of neuronal processes and increased number of protrusions, that might indicate early stage spinogenesis (Fig. 9, Supporting Movies 5A and 5B). By contrast, whole cell illumination of neurons transfected with only Cry2Phr-mCh-IBAR resulted in abundant cluster formation throughout neuronal processes (Supporting Figure 2, Supporting Movie 6). Using localized illumination conditions, we demonstrated that Cry2Phr-mCh-IBAR can be selectively activated in neuronal processes (Fig. 10, Supporting Movie 7). Taken together, this work provides evidence that the Cry2Phr-mCh-IBAR molecular optogenetic tool is suitable for the targeted manipulation of cytoskeletal structures and dynamics at the plasma membrane.

\section{Conclusion}

In this report, we describe the development of a family of optogenetic switches, collectively named as Cry-BAR, that comprise a versatile platform for controlling membrane dynamics in live cells with high spatial and temporal resolution. These switches combine homo- and heterooligomerization of the Cry2/CIB photoreceptor system with the innate PIP2 binding affinity of the I-BAR domain. As their function varies depending on the presence of various functional elements, such as WH2 binding domains, we anticipate that a modular approach can be undertaken to adapt these optogenetic switches for other applications, including the recruitment of enzyme and receptor activating and inhibitory domains. Finally, Cry-BARs are suitable tools to study membrane dynamics not only in immortalized cells, but also in sensitive and difficult to transfect primary cultures, such as neurons. Therefore the Cry-BAR optogenetic switches we report here are expected to have wide applicability for investigating cellular processes associated with membrane dynamics in a variety of experimental paradigms. 
bioRxiv preprint doi: https://doi.org/10.1101/2022.01.28.478241; this version posted January 28, 2022. The copyright holder for this preprint (which was not certified by peer review) is the author/funder. All rights reserved. No reuse allowed without permission.

FIGURE 1

A.

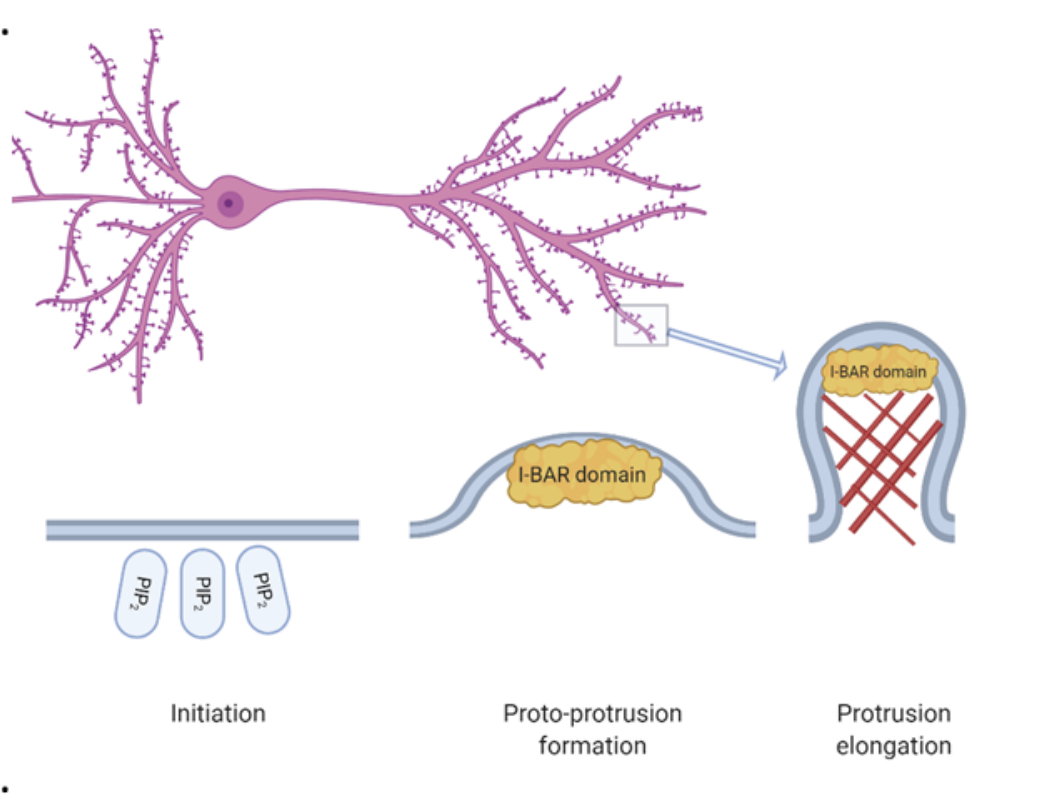

I-BAR domain

\section{\begin{tabular}{cc|c|c|} 
C. i. I-BAR & CRY2PHR \\
& &
\end{tabular}}

ii.
I-BAR
CRY2PHR
mCherry
WH2

iii.

CRY2PHR

mCherry

I-BAR

iv.

\section{CRY2PHR}

mCherry

I-BAR 
bioRxiv preprint doi: https://doi.org/10.1101/2022.01.28.478241; this version posted January 28, 2022. The copyright holder for this preprint (which was not certified by peer review) is the author/funder. All rights reserved. No reuse allowed without permission.

FIGURE 2

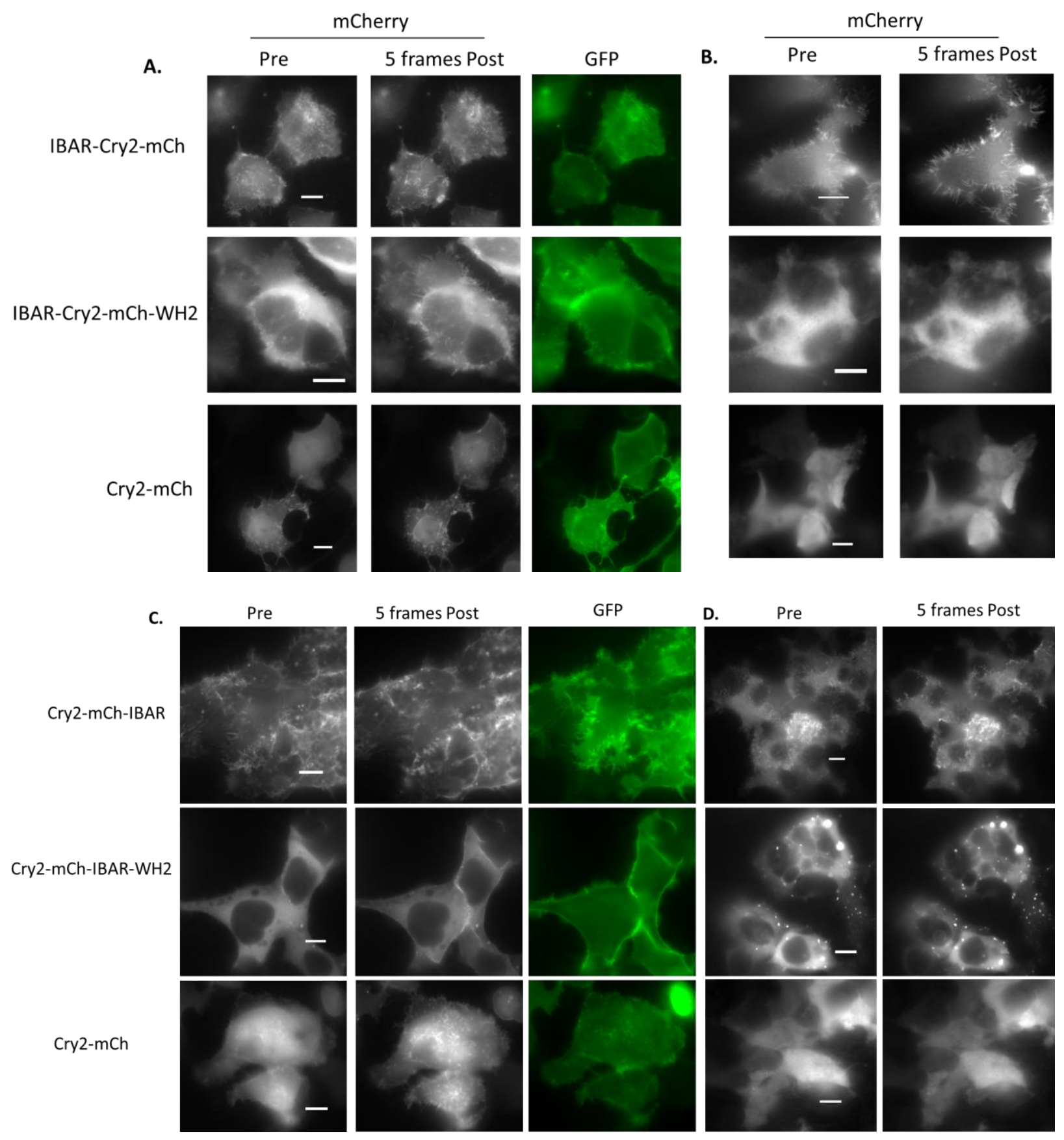


bioRxiv preprint doi: https://doi.org/10.1101/2022.01.28.478241; this version posted January 28, 2022. The copyright holder for this preprint (which was not certified by peer review) is the author/funder. All rights reserved. No reuse allowed without permission.

\section{FIGURE 3}

A.

B.
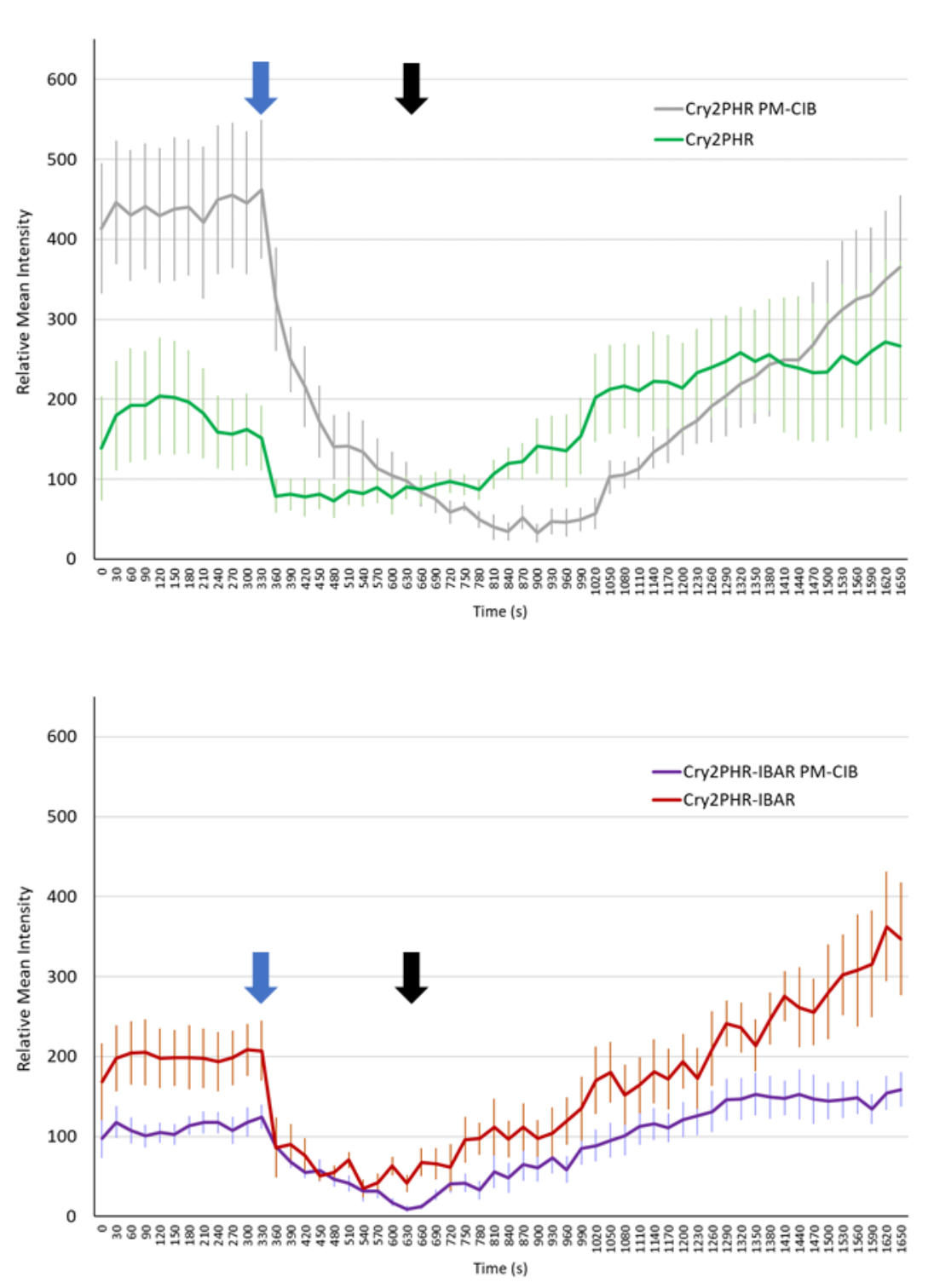
bioRxiv preprint doi: https://doi.org/10.1101/2022.01.28.478241; this version posted January 28, 2022. The copyright holder for this preprint (which was not certified by peer review) is the author/funder. All rights reserved. No reuse allowed without permission.

FIGURE 4

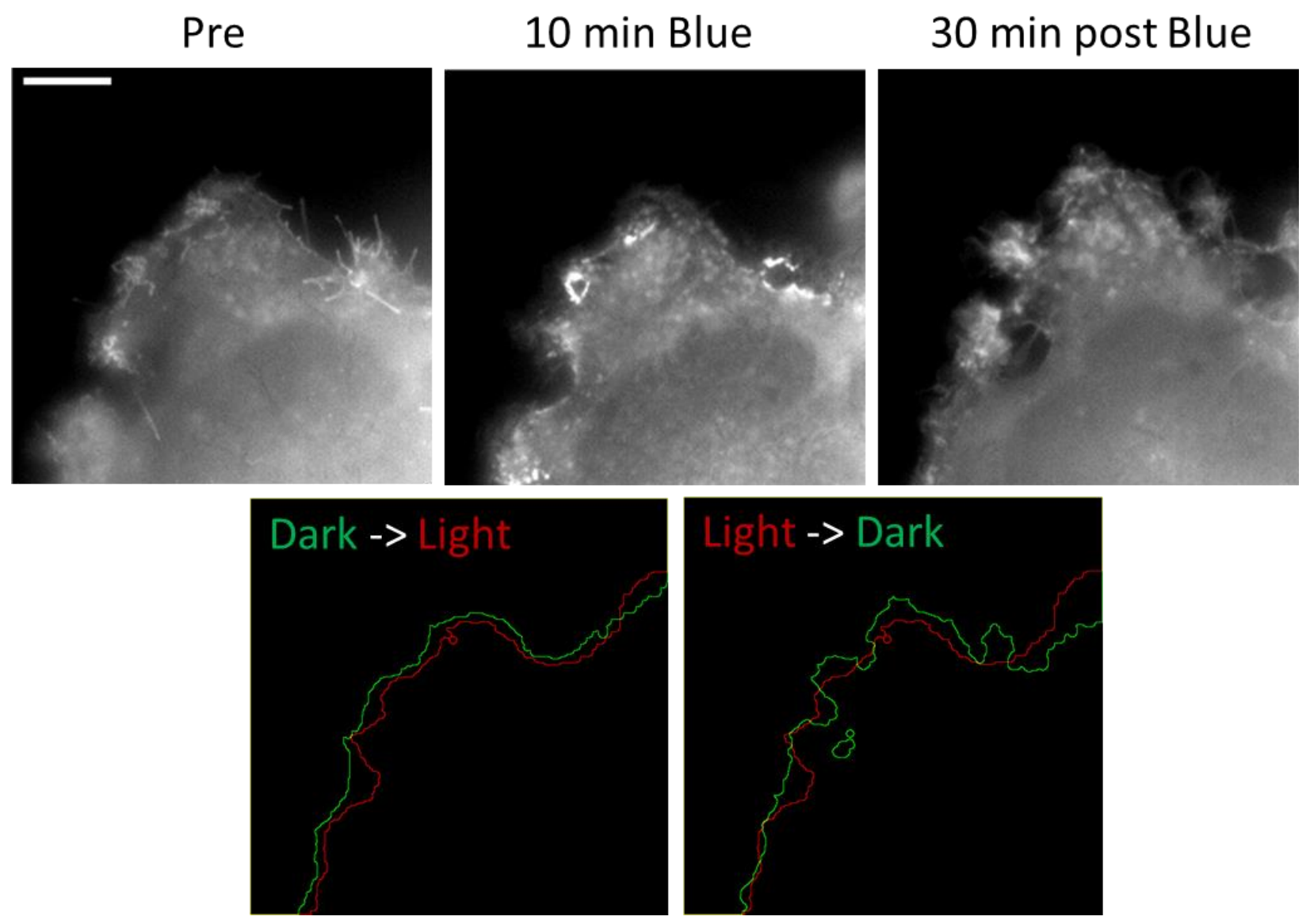


bioRxiv preprint doi: https://doi.org/10.1101/2022.01.28.478241; this version posted January 28, 2022. The copyright holder for this preprint (which was not certified by peer review) is the author/funder. All rights reserved. No reuse allowed without permission.

FIGURE 5

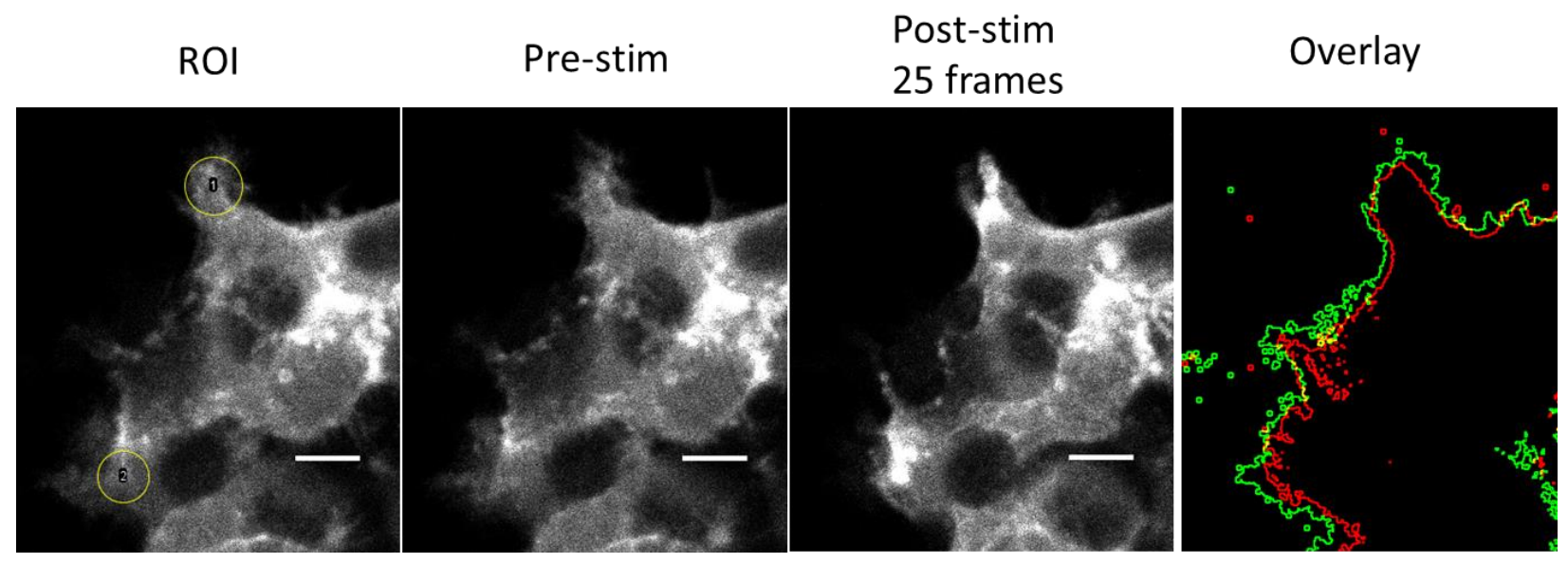


bioRxiv preprint doi: https://doi.org/10.1101/2022.01.28.478241; this version posted January 28, 2022. The copyright holder for this preprint (which was not certified by peer review) is the author/funder. All rights reserved. No reuse allowed without permission.

FIGURE 6

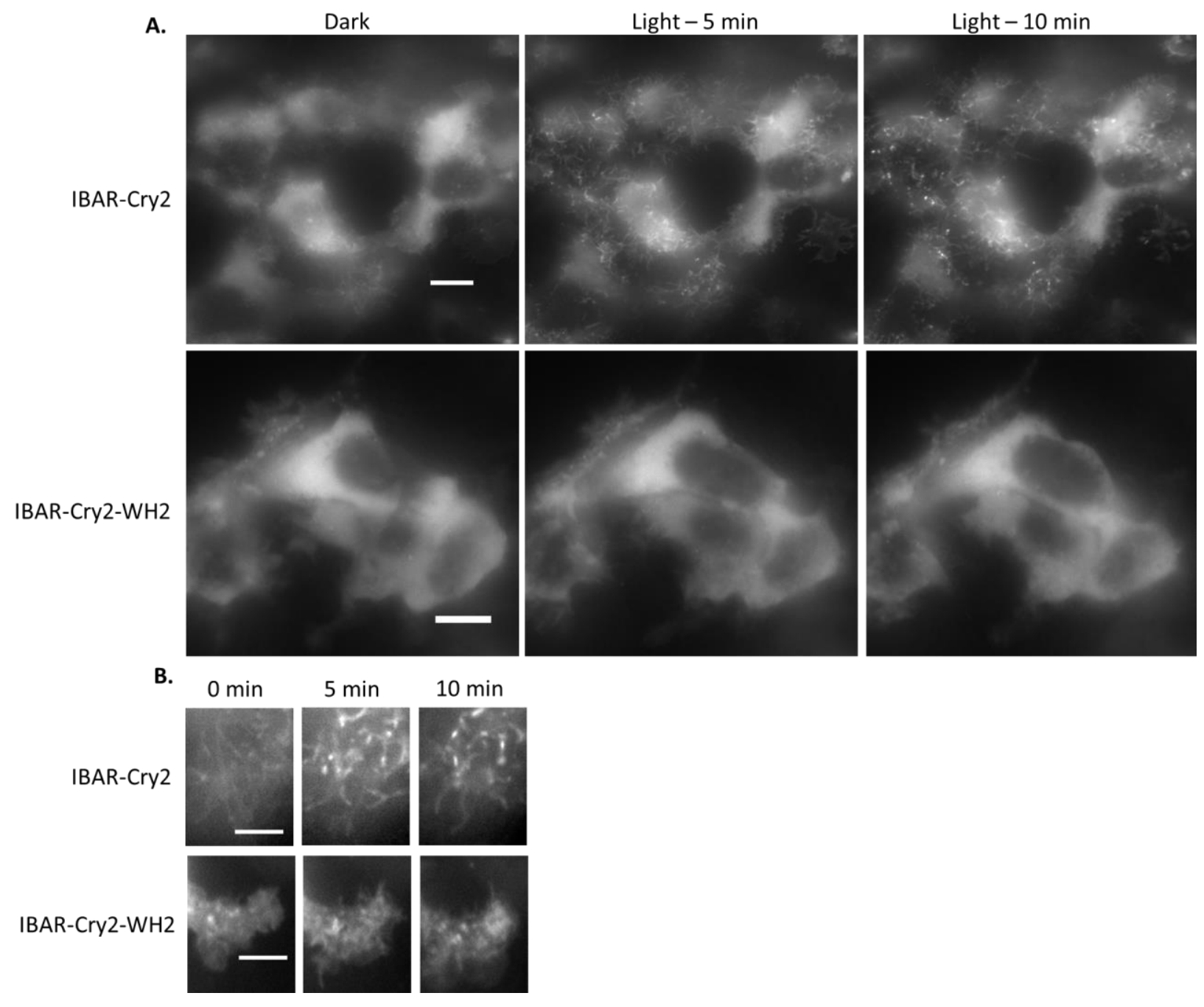




\section{FIGURE 7}

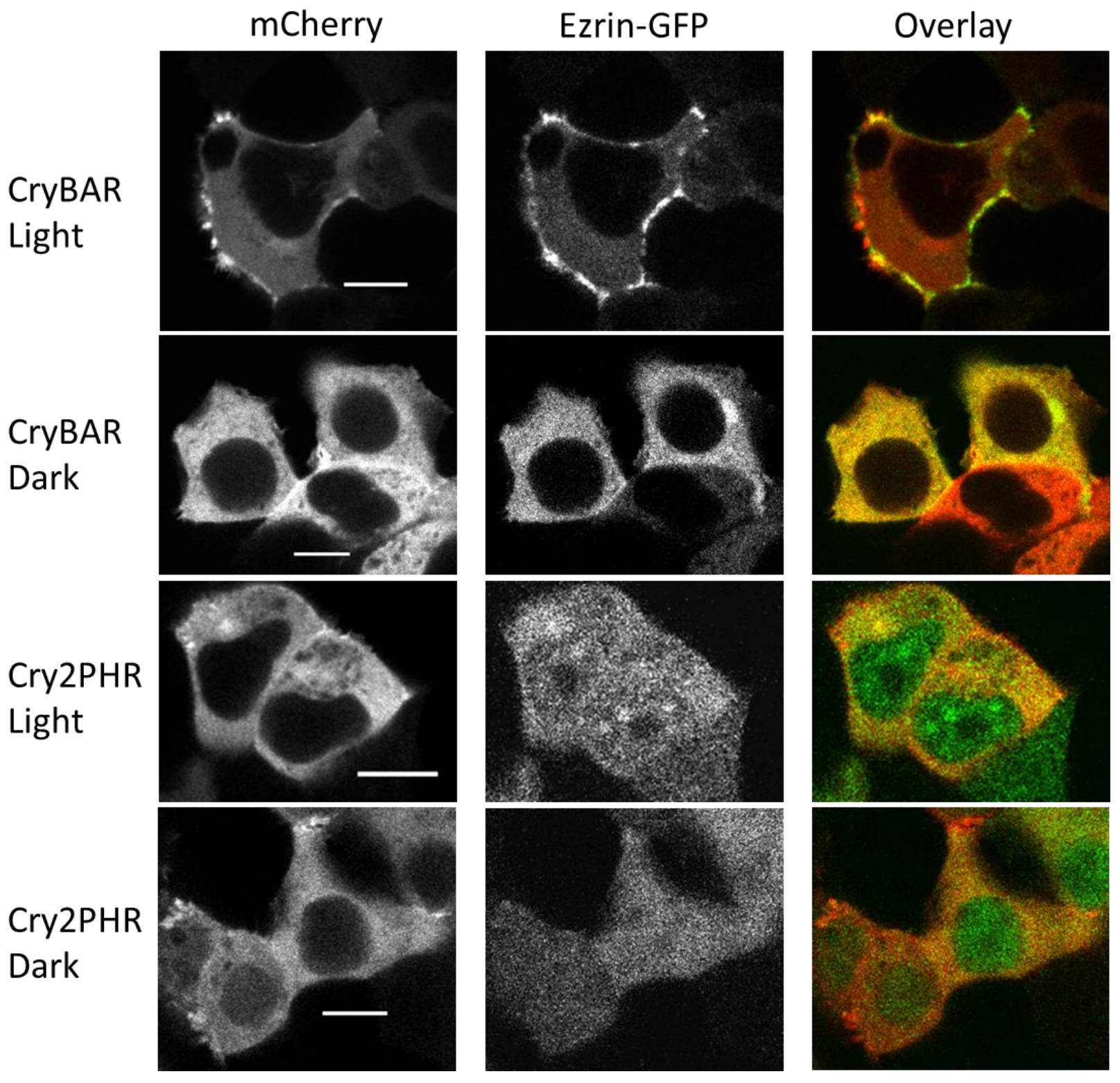


bioRxiv preprint doi: https://doi.org/10.1101/2022.01.28.478241; this version posted January 28, 2022. The copyright holder for this preprint (which was not certified by peer review) is the author/funder. All rights reserved. No reuse allowed without permission.

\section{FIGURE 8}

A.

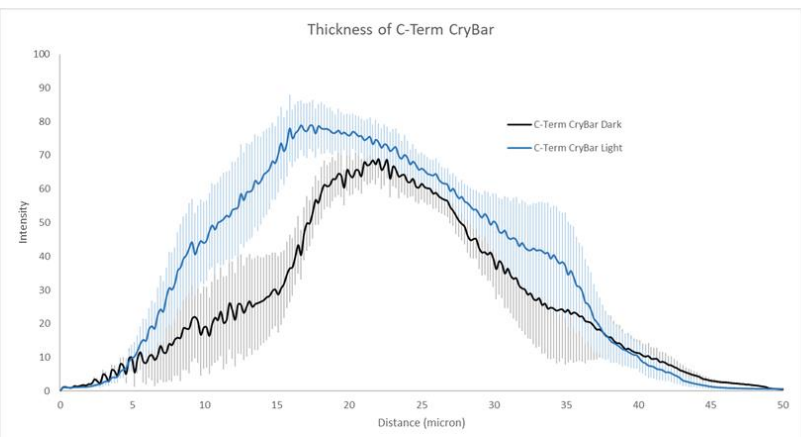

B.

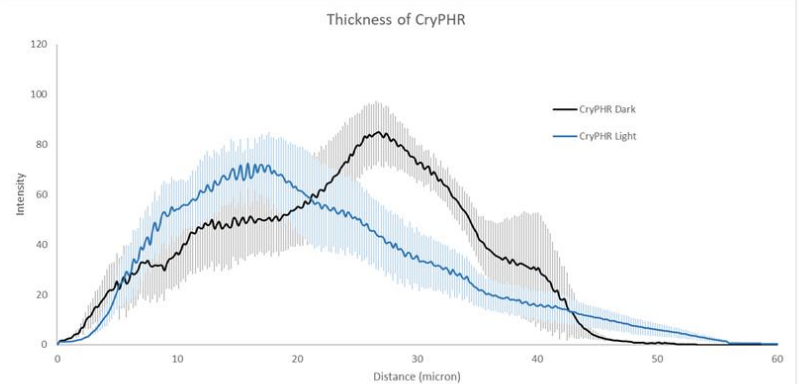

c.

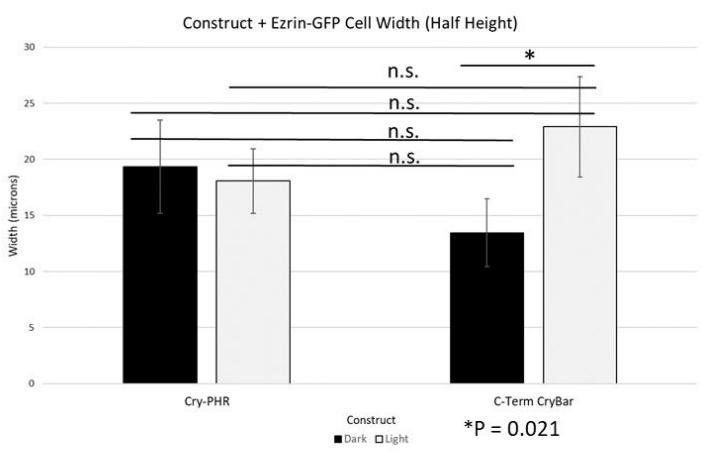

D.

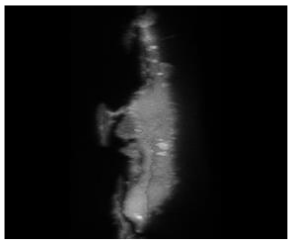

Dark

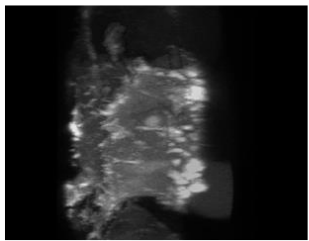

Light 
bioRxiv preprint doi: https://doi.org/10.1101/2022.01.28.478241; this version posted January 28, 2022. The copyright holder for this preprint (which was not certified by peer review) is the author/funder. All rights reserved. No reuse allowed without permission.

\section{FIGURE 9}

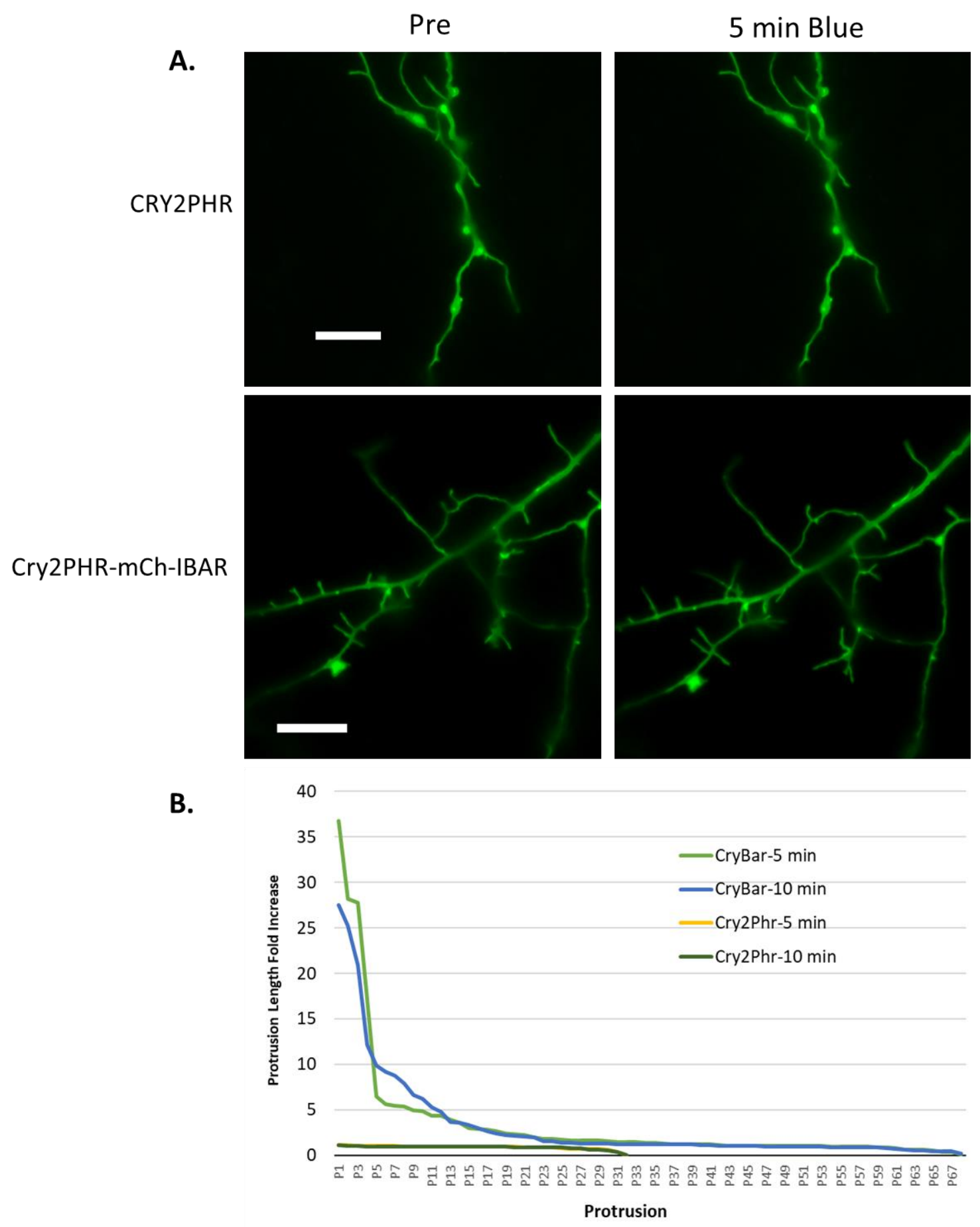


bioRxiv preprint doi: https://doi.org/10.1101/2022.01.28.478241; this version posted January 28, 2022. The copyright holder for this preprint (which was not certified by peer review) is the author/funder. All rights reserved. No reuse allowed without permission.

FIGURE 10
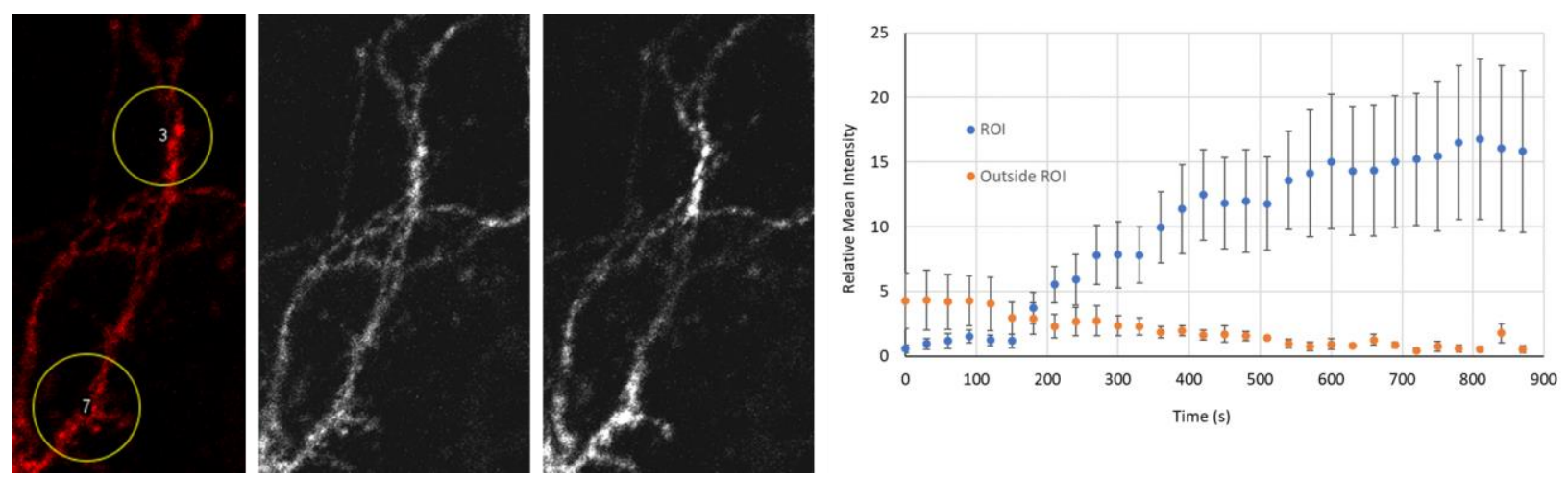


\section{Supporting Figure 1}

A.

$$
1 .
$$

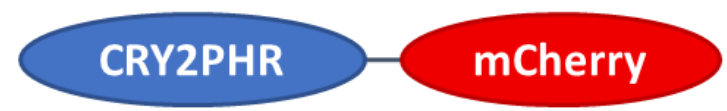

2.

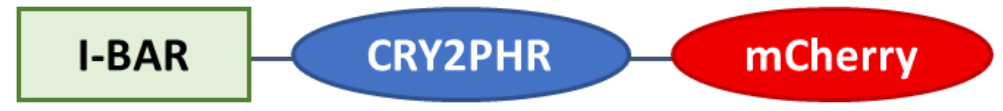

3.

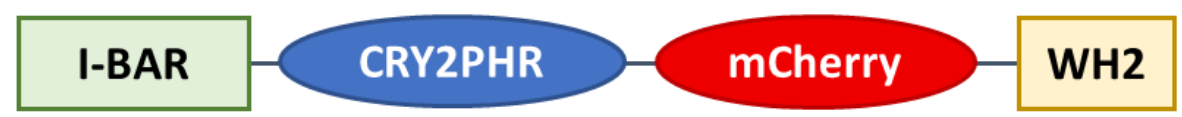

4.

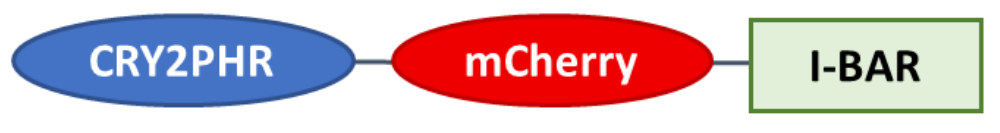

5.

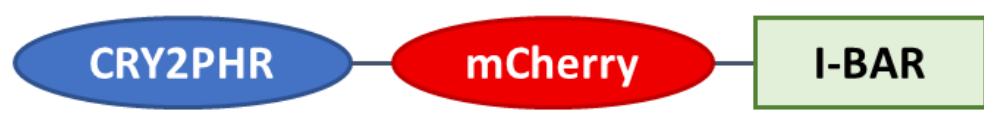

WH2

\section{No Transfection Control}

B.

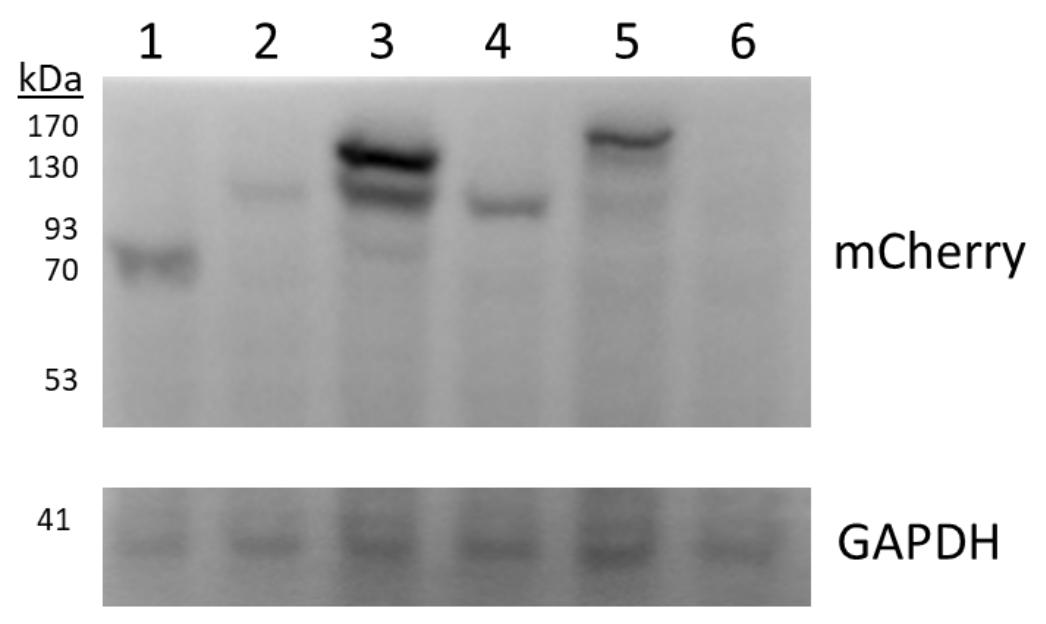


bioRxiv preprint doi: https://doi.org/10.1101/2022.01.28.478241; this version posted January 28, 2022. The copyright holder for this preprint (which was not certified by peer review) is the author/funder. All rights reserved. No reuse allowed without permission.

\section{Supporting Figure 2}

\section{Cry2-mCh-IBAR}

\section{Cry2-mCh-IBAR $+\mathrm{PM}-\mathrm{ClB}$}

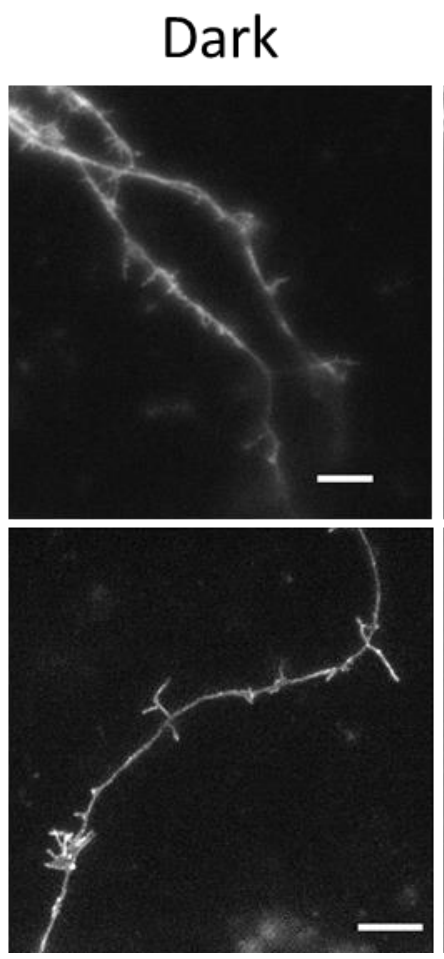

5 min Light
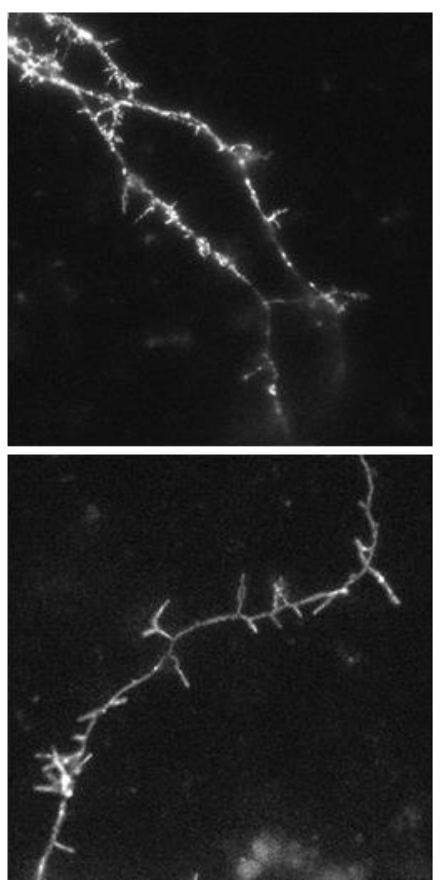
Authors' contributions: AIW, WPB, ESM, and RMH designed experiments. AIW and RMH performed cloning and cell culture experiments. WBP and ESM prepared neuron cultures and transfected neurons. AIW, WPB, ESM, and RMH analyzed data and prepared figures. All authors contributed to writing the manuscript and agreed to the content of this paper.

Acknowledgements: Authors wish to thank Mr. Collin T. O'Bryant for assistance with confocal microscopy. This work was supported by a seed grant to RMH and ESM from the East Carolina University Biomaterials Research Cluster.

Conflict of Interest Declaration: The authors declare that they have no conflict of interest with the publication of this manuscript.

Availability of Materials and Data: Experimental data are available upon request. All Cry-BAR plasmids will be available through Addgene (Watertown, MA), a nonprofit DNA repository.

\section{References}

Antonny, B. (2011). Mechanisms of membrane curvature sensing. Annual Review of Biochemistry, 80, 101-123. https://doi.org/10.1146/annurev-biochem-052809-155121

Bunner, W. P., Dodson, R., Szatmari, E. M., \& Hughes, R. M. (2021). Transfection and Activation of CofActor, a Light and Stress Gated Optogenetic Tool, in Primary Hippocampal Neuron Cultures. Bio-Protocol, in press.

Chang, J.-Y., Parra-Bueno, P., Laviv, T., Szatmari, E. M., Lee, S.-J. R., \& Yasuda, R. (2017). CaMKII Autophosphorylation Is Necessary for Optimal Integration of $\mathrm{Ca}(2+)$ Signals during LTP Induction, but Not Maintenance. Neuron, 94(4), 800-808.e4.

https://doi.org/10.1016/j.neuron.2017.04.041

Chatzi, C., Zhang, Y., Hendricks, W. D., Chen, Y., Schnell, E., Goodman, R. H., \& Westbrook, G. L. (2019). Exercise-induced enhancement of synaptic function triggered by the inverse BAR protein, Mtss1L. ELife, 8. https://doi.org/10.7554/eLife.45920

Hao, J.-J., Liu, Y., Kruhlak, M., Debell, K. E., Rellahan, B. L., \& Shaw, S. (2009). Phospholipase Cmediated hydrolysis of PIP2 releases ERM proteins from lymphocyte membrane. The Journal of Cell Biology, 184(3), 451-462. https://doi.org/10.1083/jcb.200807047

Hughes, J. H., \& Kumar, S. (2016). Synthetic mechanobiology: engineering cellular force generation and signaling. Current Opinion in Biotechnology, 40, 82-89.

https://doi.org/10.1016/j.copbio.2016.03.004 
Jones, T. 4th, Liu, A., \& Cui, B. (2020). Light-Inducible Generation of Membrane Curvature in Live Cells with Engineered BAR Domain Proteins. ACS Synthetic Biology, 9(4), 893-901. https://doi.org/10.1021/acssynbio.9b00516

Kennedy, M. J., Hughes, R. M., Peteya, L. A., Schwartz, J. W., Ehlers, M. D., \& Tucker, C. L. (2010). Rapid blue-light-mediated induction of protein interactions in living cells. Nature Methods, 7(12), 973-975. https://doi.org/10.1038/nmeth.1524

Khamo, J. S., Krishnamurthy, V. V, Chen, Q., Diao, J., \& Zhang, K. (2019). Optogenetic Delineation of Receptor Tyrosine Kinase Subcircuits in PC12 Cell Differentiation. Cell Chemical Biology, 26(3), 400-410.e3. https://doi.org/10.1016/j.chembiol.2018.11.004

Kichuk, T. C., Carrasco-López, C., \& Avalos, J. L. (2021). Lights up on organelles: Optogenetic tools to control subcellular structure and organization. WIREs Mechanisms of Disease, 13(1), e1500. https://doi.org/10.1002/wsbm.1500

Klewer, L., \& Wu, Y.-W. (2019). Light-Induced Dimerization Approaches to Control Cellular Processes. Chemistry (Weinheim an Der Bergstrasse, Germany), 25(54), 12452-12463. https://doi.org/10.1002/chem.201900562

Linkner, J., Witte, G., Zhao, H., Junemann, A., Nordholz, B., Runge-Wollmann, P., ... Faix, J. (2014). The inverse BAR domain protein IBARa drives membrane remodeling to control osmoregulation, phagocytosis and cytokinesis. Journal of Cell Science, 127(Pt 6), 12791292. https://doi.org/10.1242/jcs.140756

O’Banion, C.P., Priestman, M. A., Hughes, R. M., Herring, L. E., Capuzzi, S. J., \& Lawrence, D. S. (2017). Design and Profiling of a Subcellular Targeted Optogenetic CAMP-Dependent Protein Kinase. Cell Chemical Biology. https://doi.org/10.1016/j.chembiol.2017.09.011

O’Banion, Colin P, Vickerman, B. M., Haar, L., \& Lawrence, D. S. (2019). Compartmentalized cAMP Generation by Engineered Photoactivated Adenylyl Cyclases. Cell Chemical Biology, 26(10), 1393-1406.e7. https://doi.org/10.1016/j.chembiol.2019.07.004

Prévost, C., Zhao, H., Manzi, J., Lemichez, E., Lappalainen, P., Callan-Jones, A., \& Bassereau, P. (2015). IRSp53 senses negative membrane curvature and phase separates along membrane tubules. Nature Communications, 6, 8529. https://doi.org/10.1038/ncomms9529

Pykäläinen, A., Boczkowska, M., Zhao, H., Saarikangas, J., Rebowski, G., Jansen, M., ... Lappalainen, P. (2011). Pinkbar is an epithelial-specific BAR domain protein that generates planar membrane structures. Nature Structural \& Molecular Biology, 18(8), 902-907. https://doi.org/10.1038/nsmb.2079

Redchuk, T. A., Karasev, M. M., Verkhusha, P. V, Donnelly, S. K., Hülsemann, M., Virtanen, J., ... Verkhusha, V. V. (2020). Optogenetic regulation of endogenous proteins. Nature Communications, 11(1), 605. https://doi.org/10.1038/s41467-020-14460-4

Saarikangas, J., Kourdougli, N., Senju, Y., Chazal, G., Segerstråle, M., Minkeviciene, R., ... Hotulainen, P. (2015). MIM-Induced Membrane Bending Promotes Dendritic Spine 
Initiation. Developmental Cell, 33(6), 644-659.

https://doi.org/10.1016/j.devcel.2015.04.014

Saarikangas, J., Mattila, P. K., Varjosalo, M., Bovellan, M., Hakanen, J., Calzada-Wack, J., ... Lappalainen, P. (2011). Missing-in-metastasis MIM/MTSS1 promotes actin assembly at intercellular junctions and is required for integrity of kidney epithelia. Journal of Cell Science, 124(Pt 8), 1245-1255. https://doi.org/10.1242/jcs.082610

Salem, F. B., Bunner, W. P., Prabhu, V. V., Kuyateh, A. B., O’Bryant, C. T., Murashov, A. K., ... Hughes, R. M. (2020). CofActor: A light- And stress-gated optogenetic clustering tool to study disease-associated cytoskeletal dynamics in living cells. Journal of Biological Chemistry, 295(32), 11231-11245. https://doi.org/10.1074/jbc.ra119.012427

Shaaya, M., Fauser, J., Zhurikhina, A., Conage-Pough, J. E., Huyot, V., Brennan, M., ... Karginov, A. V. (2020). Light-regulated allosteric switch enables temporal and subcellular control of enzyme activity. ELife, 9. https://doi.org/10.7554/eLife.60647

Sun, Y., Smirnov, M., Kamasawa, N., \& Yasuda, R. (2021). Rapid Ultrastructural Changes in the PSD and Surrounding Membrane after Induction of Structural LTP in Single Dendritic Spines. The Journal of Neuroscience : The Official Journal of the Society for Neuroscience, 41(33), 7003-7014. https://doi.org/10.1523/JNEUROSCI.1964-20.2021

Tsai, F.-C., Bertin, A., Bousquet, H., Manzi, J., Senju, Y., Tsai, M.-C., ... Bassereau, P. (2018). Ezrin enrichment on curved membranes requires a specific conformation or interaction with a curvature-sensitive partner. ELife, 7. https://doi.org/10.7554/eLife.37262

Ueda, Y., \& Sato, M. (2018). Cell membrane dynamics induction using optogenetic tools. Biochemical and Biophysical Research Communications, 506(2), 387-393. https://doi.org/10.1016/j.bbrc.2017.11.091

Wu, Y. I., Frey, D., Lungu, O. I., Jaehrig, A., Schlichting, I., Kuhlman, B., \& Hahn, K. M. (2009). A genetically encoded photoactivatable Rac controls the motility of living cells. Nature, 461(7260), 104-108. https://doi.org/10.1038/nature08241

Wu, Y. I., Wang, X., He, L., Montell, D., \& Hahn, K. M. (2011). Spatiotemporal control of small GTPases with light using the LOV domain. Methods in Enzymology, 497, 393-407. https://doi.org/10.1016/B978-0-12-385075-1.00016-0

Yu, D., Zhan, X. H., Niu, S., Mikhailenko, I., Strickland, D. K., Zhu, J., ... Zhan, X. (2011). Murine missing in metastasis (MIM) mediates cell polarity and regulates the motility response to growth factors. PloS One, 6(6), e20845. https://doi.org/10.1371/journal.pone.0020845

Zhao, H., Pykäläinen, A., \& Lappalainen, P. (2011). I-BAR domain proteins: linking actin and plasma membrane dynamics. Current Opinion in Cell Biology, 23(1), 14-21. https://doi.org/10.1016/j.ceb.2010.10.005 


\section{Figure Legends}

Figure 1. BAR-mediated initiation of dendritic spine generation in neurons. $A$. Phosphoinositide (PIP2) signaling recruits I-BAR domain proteins to the plasma membrane, inducing a proto-protrusion. Subsequent recruitment of actin (red crosshatches) and actin binding and remodeling proteins promotes protrusion elongation. Mature dendritic spines (purple nodules on dendrite) are mushroom-shaped bulbous protrusions and major sites of excitatory synaptic transmission in the mammalian brain. B. Diagram of MTSS-1, an I-BAR domain containing protein. The N-terminal I-BAR domain ( 250 amino acids) is comprised of three alpha helices. MIM-S1 and MIM-S2 represent the I-BAR domain dimerization interface as determined from X-ray crystallography [34]. SRD = serine-rich domain; PRD = proline-rich domain; $\mathrm{WH} 2$ = Wiskott - Aldrich syndrome homology region. C. Schematic of CRY-BAR optogenetic switches: $\mathrm{i}$. The N-terminal I-BAR domain ( 250 amino acids) is fused to photoreceptor protein CRY2, which is fused to the red fluorescent mCherry protein for visualization purposed. ii. At the C-terminus, proline-rich and $\mathrm{WH} 2$ domains can be included for actin-recruitment. iii. The N-terminal I-BAR domain is fused to the C-terminus of mCherry. iv. The intact MTSS1 protein is fused to the C-terminus of mCherry. Graphic in panel A generated with BioRender (https://biorender.com/).

Figure 2. Light-activated responses of CRY-BAR constructs. A. HEK293T cells were cotransfected with CIB-CAAX and CRY-BAR fusions 1 and 2, respectively, and imaged on a widefield fluorescent microscope. B. HEK293T cells were transfected with CRY-BAR fusions 1 and 2, respectively and imaged on a widefield fluorescent microscope. C. HEK293T cells were co-transfected with CIB-CAAX and CRY-BAR fusions 3 and 4, respectively, and imaged on a widefield fluorescent microscope. D. HEK293T cells were transfected with CRY-BAR fusions 3 and 4 , respectively and imaged on a widefield fluorescent microscope. Pre = image before 480 $\mathrm{nm}$ light exposure; Post = image after $480 \mathrm{~nm}$ light exposure. Images acquired every $30 \mathrm{~s}$. Scale bars $=10$ microns.

Figure 3. Analysis of Light-activated responses of CRY-BAR constructs. A. Cry2PHR construct shows large decrease in cytosolic fluorescence intensity in the presence of plasma membrane anchored CIB, but not in its absence. B. Cry2PHR-mCherry-IBAR construct shows smaller decrease in cytosolic fluorescence intensity (relative to Cry2PHR-mCherry) in the presence and absence of plasma membrane anchored CIB, indicative of significant pre-localization to plasma membrane. Blue arrows indicate beginning of blue light illumination (50 ms exposure of $480 \mathrm{~nm}$ light every $30 \mathrm{~s}$ ); black arrows indicate end of blue light illumination. Graphs show changes in normalized cytosolic mCherry fluorescence.

Figure 4. Reversible light-activated membrane remodeling with CRY-BAR. HEK293T cells transfected with Cry2PHR-mCh-IBAR were subjected to blue light illumination for 10 minutes, followed by 30 minutes without blue light. Membrane retraction and reshaping is observed during blue light illumination, followed by recovery in the absence of blue light. Scale bar $=10$ microns. 
Figure 5. Localized light-activation of membrane remodeling with CRY-BAR. HEK293T cells transfected with Cry2PHR-mCh-IBAR were subjected to restricted blue light illumination (yellow circles) using a confocal microscope. Clustering of CRY-BAR is apparent in the areas irradiated with blue light. An overlay of the cell outline is shown before (green) and after (red) blue light illumination. Frames acquired every $30 \mathrm{~s}$. Scale bar $=10$ microns.

Figure 6. Light-activation of $\mathrm{N}$-terminal IBAR-Cry2 fusions with and without a C-terminal WH2 domain. A. HEK293T cells transfected with IBAR-Cry2PHR-mCh or IBAR-Cry2PHR-mCh-WH2 were subjected to blue light illumination ( 50 ms every $30 \mathrm{~s}$ ) using a widefield microscope. IBARCry2PHR-mCh rapidly accumulates into dynamic filopodial structures. Scale bars $=10$ microns. B. The presence of a $\mathrm{WH} 2$ domain inhibits accumulation into filopodial structures and subsequent coalescence. Scale bars $=5$ microns.

Figure 7. CRY-BAR activation linked to Ezrin. HEK293T cells co-transfected with Cry2PHR-mChIBAR and Ezrin-GFP were subjected to blue light illumination or dark followed by fixation. Confocal microscopy reveals co-localization of CRY-BAR and Ezrin-GFP as a result of CRY-BAR activation. Scale bar $=10$ microns.

Figure 8. CRY-BAR activation and cell thickness. HEK293T cells co-transfected with Cry2PHRmCh-IBAR and Ezrin-GFP were subjected to blue light illumination or dark followed by fixation. Cellular thickness was analyzed for $n=4$ cells per experimental condition. A. Average cellular thickness of Cry2-mCherry-IBar transfected HEK293T cells before and after illumination. B. Average cellular thickness of Cry2Phr transfected HEK293T cells before and after illumination. C. Analysis of average cellular thickness at half height (One way ANOVA; *P=0.021). D. Representative images of Z-projections of Ezrin-GFP distribution in Cry2-mCherry-Ibar transfected cells before and after illumination and fixation.

Figure 9. C-term CRY-BAR plasma membrane recruitment in neurons. A. Pre- and 5 min-post blue light illumination of processes in hippocampal neurons co-transfected with Cry2-mCherryIBAR and CIB-GFP-CAAX (GFP channel shown). B. Fold-increase in protrusion length in protrusions of CRY-BAR (blue and green lines) or Cry2Phr (yellow and black lines) expressing neurons co-transfected with CIB-GFP-CAAX after 5 and 10 minutes of blue light illumination. $30 / 68$ protrusions (44\%) in the CRY-BAR neurons showed an increase of 1.5 -fold or higher, whereas $0 / 32$ protrusions $(0 \%)$ in the Cry2Phr neurons showed an increase of 1.5 -fold or higher.

Figure 10. Localized light-activation of CRY-BAR in primary neurons. Neurons transfected with Cry2PHR-mCh-IBAR were subjected to restricted blue light illumination (yellow circles) using a confocal microscope. Clustering of CRY-BAR is apparent in the areas illuminated 15 min postblue light stimulation. A plot of fluorescence intensity from four illuminated ROIs vs. four nonilluminated regions is shown at right (error bars = SEM). Scale bar $=10$ microns.

Supporting Figure 1. CRY-BAR construct design and expression. A. Diagrams of the CRY-BAR protein fusions; Constructs 2, 3, and 4 contain portions of the MTSS-1 protein (I-BAR, WH2, or 
both); Construct 5 contains the full length MTSS-1 protein. B. Lysates of HEK293T cells transfected with CRY-BAR constructs and controls (Lanes 1-6, numbers correspond to panel A) were western blotted with anti-mCherry antibody. Expected Molecular Weights: 1. $111 \mathrm{kD} ; 2$. 85 kD; 3. 130 kD; 4.111 kD; 5.168 kD; 6. No transfect.

Supporting Figure 2. Global activation of CRY-BAR in hippocampal neurons. Neurons transfected with Cry2-mCh-IBAR; and co-transfected with Cry2-mCh-IBAR + PM-CIB were illuminated every thirty seconds with $470 \mathrm{~nm}$ light on a widefield microscope. After 5 minutes, Cry2-mCh-IBAR forms numerous clusters throughout the neuronal processes, whereas in the presence of PM-CIB no such clusters are formed. Scale bar $=10$ microns.

\section{Supporting Movie Legends}

Supporting Movie 1A Cry2PHR-mCh-IBAR light activation in HEK293T cells

Supporting Movie 1B Cry2PHR-mCh-IBAR light activation in HEK293T cells

Supporting Movie 2 Cry2PHR-mCh-IBAR light activation in HEK293T cells - zoomed in region

Supporting Movie 3 Localized Cry2PHR-mCh-IBAR light activation in HEK293T cells

Supporting Movie 4 Side-by-side light activation of CRY-BARs in HEK293T cells

Supporting Movie 5A Light activation of Cry2PHR-mCh-IBAR/CIB-CAAX in neuronal process

Supporting Movie 5B Light activation of Cry2PHR-mCh-IBAR/CIB-CAAX in neuronal process

Supporting Movie 6 Light activation of Cry2PHR-mCh-IBAR in neuronal processes

Supporting Movie 7 Localized Cry2PHR-mCh-IBAR light activation in neuronal process 